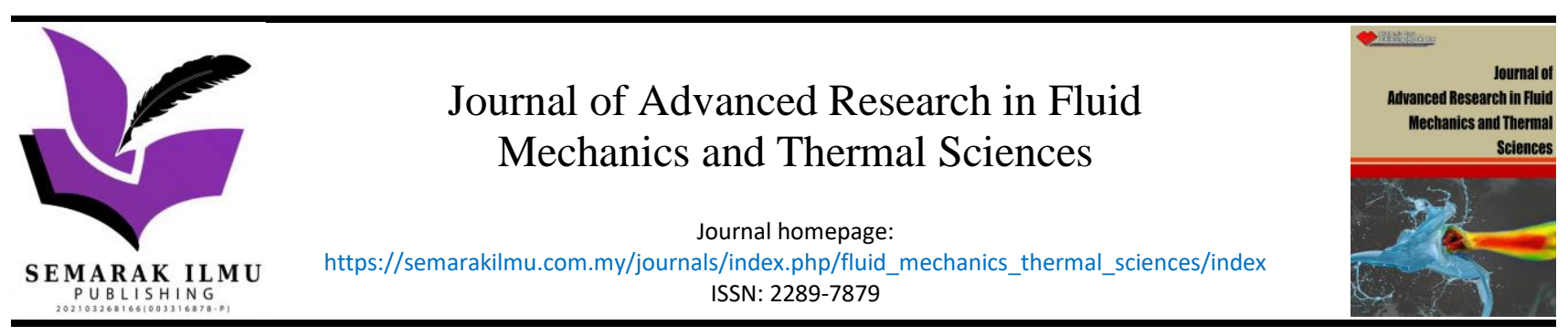

\title{
Water Overlapping Area for The Arrangement of Field's Sprinkler Irrigation
}

\author{
Nur Lina Abdullah ${ }^{1,}$, Norul Fadhilah Ismail ${ }^{2}$, Saiful Bahri Safaron ${ }^{3}$, Nurazeera Md Suder $^{3}$, Nurul \\ Wahidah Omar ${ }^{3}$ \\ 1 Faculty of Computer and Mathematical Sciences, Universiti Teknologi MARA, Cawangan Negeri Sembilan, Kampus Seremban, Persiaran \\ Seremban Tiga-1, 70300 Seremban, Negeri Sembilan, Malaysia \\ 2 Faculty of Computer and Mathematical Sciences, Universiti Teknologi MARA, Cawangan Negeri Sembilan, Kampus Kuala Pilah, Pekan Parit \\ Tinggi, 72000 Kuala Pilah, Negeri Sembilan, Malaysia \\ 3 Faculty of Computer and Mathematical Sciences, Universiti Teknologi MARA, 45450 Shah Alam, Selangor, Malaysia
}

\section{ARTICLE INFO ABSTRACT}

\section{Article history:}

Received 27 May 2021

Received in revised form 6 September 2021

Accepted 8 September 2021

Available online 21 October 2021

\section{Keywords:}

Sprinkler irrigation system; irrigation methods; water projection; water overlapping area

\begin{abstract}
The design and arrangement of sprinkler irrigation systems are presented and discussed in this paper. The design is based on a rotating sprinkler system to irrigate the field. Information is provided concerning the components of irrigation systems and the characteristics of the system that affect water application efficiency. The mathematical model is developed to account for water overlapping area throughout a fixed sprinkler system and to evaluate the number of sprinkler irrigation for the whole field using water projection profiles from the experimental data analysis. As a result, a set of recommendations for the design of sprinkler irrigation system management are obtained. Finally, this problem is alleviated using the Maplet interface. By simply typing information in the text boxes and using drop-down menus in Maplet windows, the characteristic of sprinkler irrigation systems can be studied with relative ease.
\end{abstract}

\section{Introduction}

Irrigation system basically means providing water directly to crops or indirectly through land or soil. There are three basic types of irrigation system namely sprinkler, drip, and surface. Surface irrigation is the most common used method that relies on gravity flow to distribute water as it is suited to mild slopes as well as regular slopes. While sprinkler irrigation involves spraying the plants with water using a permanently or temporarily fixed tool. Water is pumped through pipes and sprinkled onto the plants like raindrops from a spray head. However, drip irrigation involves the use of pipes with small opening at low rates on the soil. These types of irrigation have their advantage and disadvantage to be considered to ensure the water is evenly distribute without any wastage and affect the plant and soil. A systematic and effective irrigation system will ensure the growth and plant development could not be hampered or interrupt because water needs are met on the ground [1].

\footnotetext{
* Corresponding author.

E-mail address: lina7837@uitm.edu.my

https://doi.org/10.37934/arfmts.88.1.140148
} 
Sprinkler system is basically used for field applications, based on the size and shape of the irrigated area includes the flowrate and pressure of water supply. Sprinkler irrigation system can save up to $60 \%$ of water compared to surface irrigation method and increased water productivity since it is economical at large scale and widely accepted by the irrigation sector [2,3]. In addition to water saving, sprinkler irrigation also offers several other benefits, such as protecting the soil from erosion, avoiding deep absorption, suitable for uneven topography and sloping soils, reduce the use of manpower, producing healthier crops and greater yields [4].

Although there are various benefits in irrigation, an efficient management system is needed to avoid excessive or insufficient water consumption [5]. Therefore, irrigation scheduling plays an important role, which allows one to provide water for different crops according to their needs [6]. Irrigation scheduling means decision to irrigate based on appropriate time, how to irrigate and the amount of water needed according to the needs of the crops. Irrigation scheduling can be done using different approaches, but often based on reference evapotranspiration (ETo), which is usually calculated using meteorological data [7-9]. Climatological approach has been used to measure the value of pan-evaporation which is the irrigation is schedule based on necessity of the crop [10]. Based on daily basis pan evaporation data, the irrigation of the crop is done on every alternate day. However, the best irrigation scheduling criteria are based on the availability of water in the soil, which provides the highest efficiency of the irrigation system [11].

There have been many studies on irrigation scheduling, uniformity, water distribution pattern and sprinkler arrangement layout [12-17]. The objective of a sprinkler irrigation system is to channel water to the farm efficiently and uniformly. Proper spacing of sprinkler heads is a key component of uniformity and leads to a more efficient system [18]. Studied by lqbal et al., [19] emphasize that the water is more uniformly distributed in tunnel farms compared to open area by using micro sprinkler irrigation system. The difference of uniformities in the open area and tunnel increases as the system pressure increases since the wind may disturb the application rate of micro sprinkler in the open area. Non-uniformity irrigation may lead to water loss or over irrigation to plant or soil. In [20], irrigation uniformity can be calculated based on the water distributed on the soil surface by using the catch-can method or based on water distributed in the soil using soil moisture content. Measuring soil moisture uniformity can be used to determine the timing and amount of irrigation that helps in water savings and cost reduction.

Basically, there are four types of water distribution pattern which are full-circle, half-circle, three quarter-circle and quarter-circle. These patterns are design to avoid overspray beyond the irrigated area. A mathematical model has been adopted to simulate water distribution pattern under a single sprinkler irrigation system by using fourth order Runge-Kutta numerical integration technique to solve the equation that determine the drop movement derived from their dynamic balance [21]. To make the irrigation system is more efficiently, it is important to have a good strategy in managing sprinkler arrangement and the amount of water use. Thus, this paper is aimed to study the sprinkler arrangement for field using water projection profiles from the experimental data analysis.

This paper is organized as follows. In section 2, we present the methodology of this study. The mathematical model of irrigated area is discussed in section 3 and 4 . In section 5, we discuss our results for four different sprinkler arrangements. The conclusion and some recommendations for future study are presented in section 6.

\section{Materials and Methods}

In the study presented herein, the area covered was a field with rectangular shape with the size of 110-meter length and 72-meter width. Currently, there are 35 number of sprinklers used with $7 \times 5$ 
sprinklers arrangement where 4 sprinklers at the edge, 16 sprinklers at the side, and 15 sprinklers inside the rectangular. The average distances between each sprinkler are 18 meter and 16.25 meter, respectively. Each sprinkler has different rotational degree based on their location. The water distribution pattern used are full-circle (360-degree), half-circle (180 degree) and quarter-circle (90degree). The study site is illustrated in Figure 1.

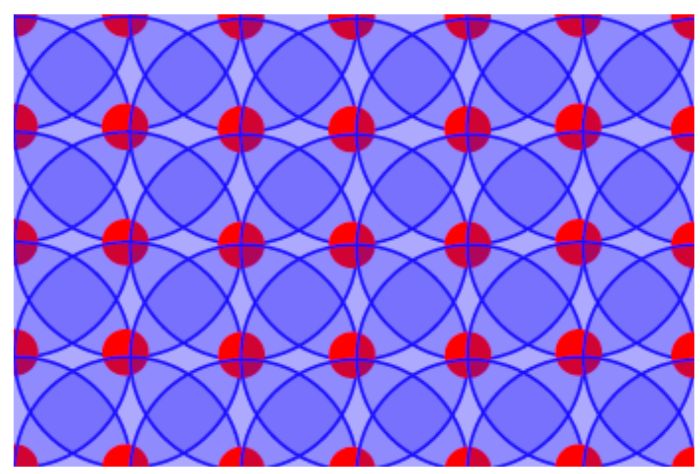

Fig. 1. Plan view diagram of the field area

On the other hand, model parameter used in this study includes radius of water projection, water pressure and water flowrate. The radius of water projection is from 11.9 to 21.7 meter, the water pressure is from 3.5 to 6.2 bars, the water flowrate is from 0.86 to $5.04 \mathrm{~m}^{3} \mathrm{~h}^{-1}$ and the outlet trajectory of 25-degree was conducted.

The basic equations were used, and mathematical model was developed in this study for some of the calculations of the result discussed herein.

\section{Mathematical Model}

A mathematical model was developed using geometry and algebra approach. For a detailed discussion of this method, we refer the reader to Abdullah et al., [22]. To fix ideas, a new sprinkler arrangement in Figure 2 is designed with the following assumptions: (a) the possible sprinkler arrangement must be less than $7 \times 5$ sprinklers; (b) the water pressure and water flowrate for each sprinkler are same and constant; (c) the same amount of water for lawn watering; (d) the amount of overlapping area must be less than $7920 \mathrm{~m}^{2}$; and (e) by increasing the distance between sprinklers, it can reduce the water overlapping area.

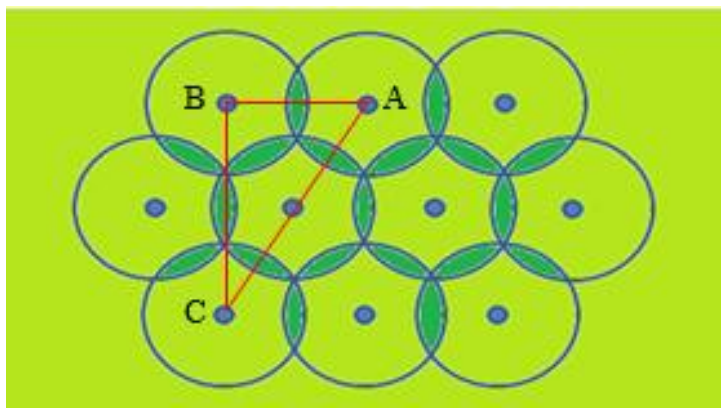

Fig. 2. New sprinkler arrangement layout

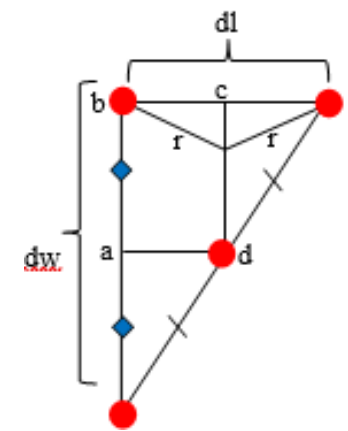

Sprinkles Meet Point

Fig. 3. Radius and meet point for four blades 


\section{Field Implementation of Irrigation Arrangement}

This section summarized the formulation developed in this study.

\subsection{Number of Sprinklers}

The number of sprinklers is calculated by

$s=(2 \times s l \times s w)-s l-s w+1$

where $s l$ is the number of sprinklers at the length of the field and $s w$ is the number of sprinklers at the width of the field.

\subsection{Distance between Each Sprinkler}

The distance between two sprinklers at the length of the field, $d l$ and the distance between two sprinklers at the width of the field, $d w$ are calculated by (2) and (3) respectively,

$d l=\frac{L}{s l-1}$

$d w=\frac{W}{s w-1}$

where $L$ is the length of the field and $W$ is the width of the field.

\subsection{Radius of Water Projection}

The radius of water projection is derived using Pythagoras Theorem and basic geometry formula. Figure 2 illustrates the radius of blade with two meet points.

Let $r$ be a radius of water projection, then

$r=\frac{d l^{2}+d w^{2}}{4 \times d w}$

There are two conditions that must be satisfied which are: (a) $d l / 2<r<d l$ and (b) $r<d w / 2$. Both conditions are important because if the radius of water projection is more than the distance between sprinklers, then the projected water will cross to the next irrigated area. Due to this situation, it will form overspray and leads to waste of water.

\subsection{Overlapping Area}

The overlapping area is made up of the intersection of two or more circles. It happens when the water distribution overlaps each other between each sprinkler as shown in Figure 4, Figure 5 and Figure 6. Figure 2 shows the suggested overlapping area between four blades. 


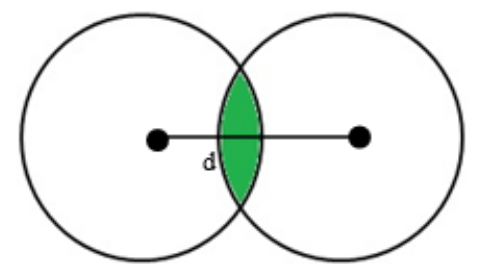

Fig. 4. Overview of overlapping area for two sprinklers

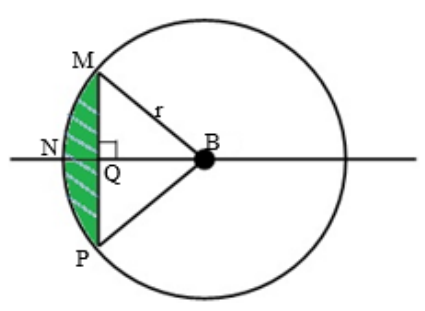

Fig. 5. Overview of overlapping area for halfblade

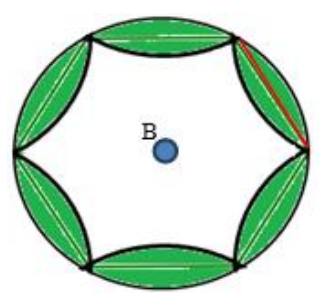

Fig. 6. Overview of overlapping area for 360-degree rotation

\subsection{Overlapping Area for One Blade}

Figure 5 and Figure 6 show an overview for one circle of irrigation area for 360-degree rotation. Since the overlapped areas are having two equal parts, therefore the sum of two overlapped areas is equal to the overlapping area of one blade.

The overlapping area for half blade is calculated by

Area of $M N P=$ Area of $B M N P-$ Area of $B M P$

$=r^{2} \cos ^{-1}\left(\frac{d}{2 r}\right)-\frac{d}{2} \sqrt{r^{2}-\frac{d^{2}}{4}}$

Hence, the overlapping area for one horizontal blade is defined as

$2 r^{2} \cos ^{-1}\left(\frac{d}{2 r}\right)-d \sqrt{r^{2}-\frac{d^{2}}{4}}$

where the value is double the area of $M N P$. Since the distance between each sprinkler at length and width are different, so to calculate the overlapping area for one vertical blade, $d$ is substituted by $\frac{1}{2} \sqrt{d l^{2}+d w^{2}}$. Hence, the overlapping area for one vertical blade is defined as

$2 r^{2} \cos ^{-1}\left(\frac{\sqrt{d l^{2}+d w^{2}}}{4 r}\right)-\frac{\sqrt{d l^{2}+d w^{2}}}{2} \sqrt{r^{2}-\frac{d l^{2}+d w^{2}}{16}}$

From Eq. (6) and Eq. (7), therefore the total overlapping areas is obtained as

$$
\begin{aligned}
& (s w-1)(2 s l-3)\left(2 r^{2} \cos ^{-1}\left(\frac{d}{2 r}\right)-d \sqrt{r^{2}-\frac{d^{2}}{4}}\right)+ \\
& 4(s l-1)(s w-1)\left(2 r^{2} \cos ^{-1}\left(\frac{\sqrt{d l^{2}+d w^{2}}}{4 r}\right)-\frac{\sqrt{d l^{2}+d w^{2}}}{2} \sqrt{r^{2}-\frac{d l^{2}+d w^{2}}{16}}\right)
\end{aligned}
$$

where $4(s l-1)(s w-1)$ is the number of horizontal blades and $(s w-1)(2 s l-3)$ is the number of vertical blades. 


\section{Result and Discussion}

In this study, various possible number of sprinklers with $a \times b$ arrangements are tested. As a result, there are four different arrangements which are $6 \times 3,6 \times 2,5 \times 3$ and $5 \times 2$ are considered. All the data obtained are summarized in Table 1 . In general, the minimum number of sprinklers needed is 14 , and the maximum number of sprinklers is 28 . Based on the model, average number of sprinklers are in the range of 14 sprinklers to 28 sprinklers which are less than 35 sprinklers. In most of these cases, the overlapping area were less than the current overlapping area, $7200 \mathrm{~m}^{2}$ and acceptable for sprinkler irrigation. As shown in Table 1, the amount of overlapping areas is from $1693.115662 \mathrm{~m}^{2}$ to $3849.800975 \mathrm{~m}^{2}$ and this indicates that, these models may result in water savings and reducing the maintenance cost.

Table 1

Possible sprinkler arrangements

\begin{tabular}{lllllll}
\hline$s l$ & $s w$ & $\begin{array}{l}\text { Number of } \\
\text { sprinklers }\end{array}$ & $\begin{array}{l}d l \\
(m)\end{array}$ & $\begin{array}{l}d w \\
(m)\end{array}$ & $\begin{array}{l}\text { Radius of water } \\
\text { projection, }(m)\end{array}$ & $\begin{array}{l}\text { Overlapping area, } \\
\left(m^{2}\right)\end{array}$ \\
\hline 6 & 3 & 28 & 22 & 36 & 12.36111111 & 1639.115662 \\
6 & 2 & 17 & 22 & 72 & 19.68055556 & 3849.800975 \\
5 & 3 & 23 & 27.5 & 36 & 14.25173611 & 2279.455848 \\
5 & 2 & 14 & 27.5 & 72 & 20.62586806 & 2479.263365 \\
\hline
\end{tabular}

The radius of water projection values ranging between 11.9 and 21.7-meter. As can be seen, all acceptable radius of water projection satisfied the condition, $r<d w / 2$. If $r>d w / 2$, the distribution of water application within a sprinkler overlap area is high. Figure 7 shows an image of sprinkler arrangement for $r>d w / 2$ where the overlapping area is big which applied additional water cost.

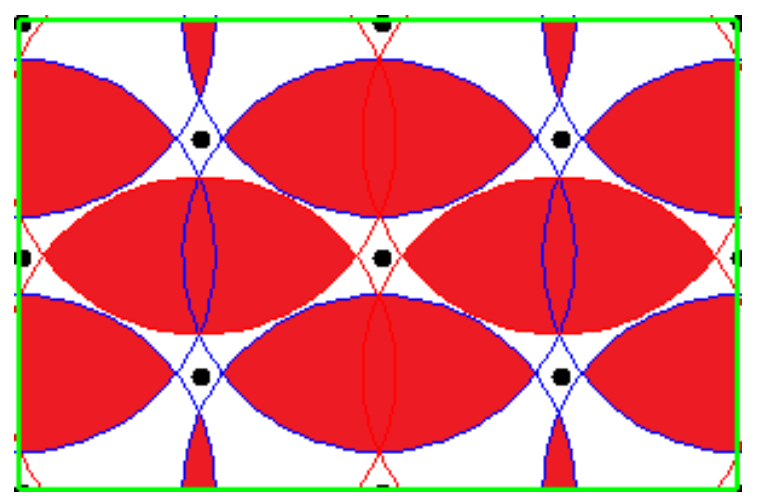

Fig. 7. Overlapping area for $r>d w / 2$

Observed that, the overlapping area has a large influence on sprinkler and lateral spacing. Besides that, the diameter of coverage also depends on the velocity of the sprinkler jet, the angle of the nozzle axis above the horizon and the size of droplets that form when the sprinkler jet breaks up. Up to a point as the diameter of coverage increases, and more uniformity application may result.

For further understanding, sprinkler arrangement models are visualized using a mathematical software, namely Maple. This interactive interface is easily accessible. To run this Maplet, user need to choose the number of sprinklers. After that, by clicking all buttons in the interface, the Maplet interface window is initialized as shown in Figure 8 and Figure 9. 


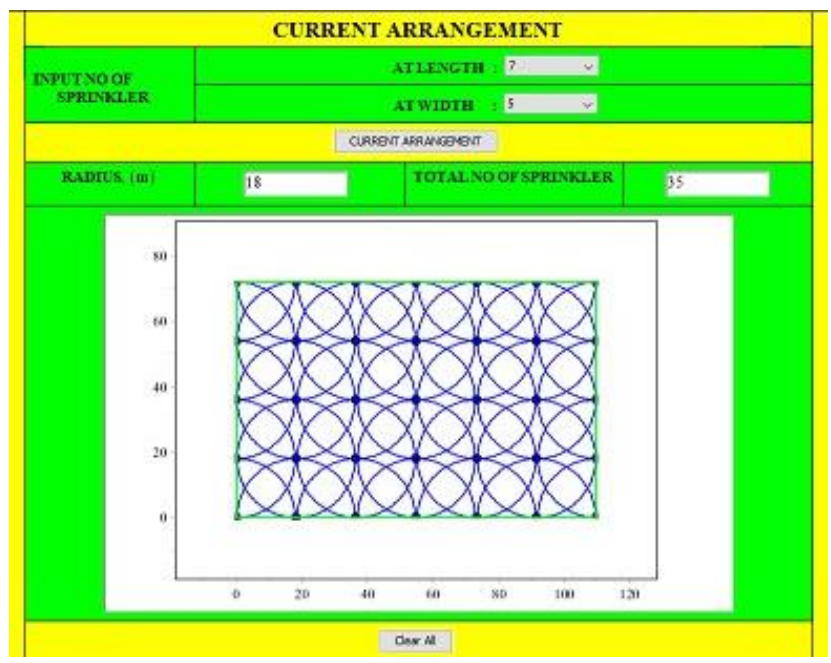

Fig. 8. Maplet interface for current sprinkler arrangement

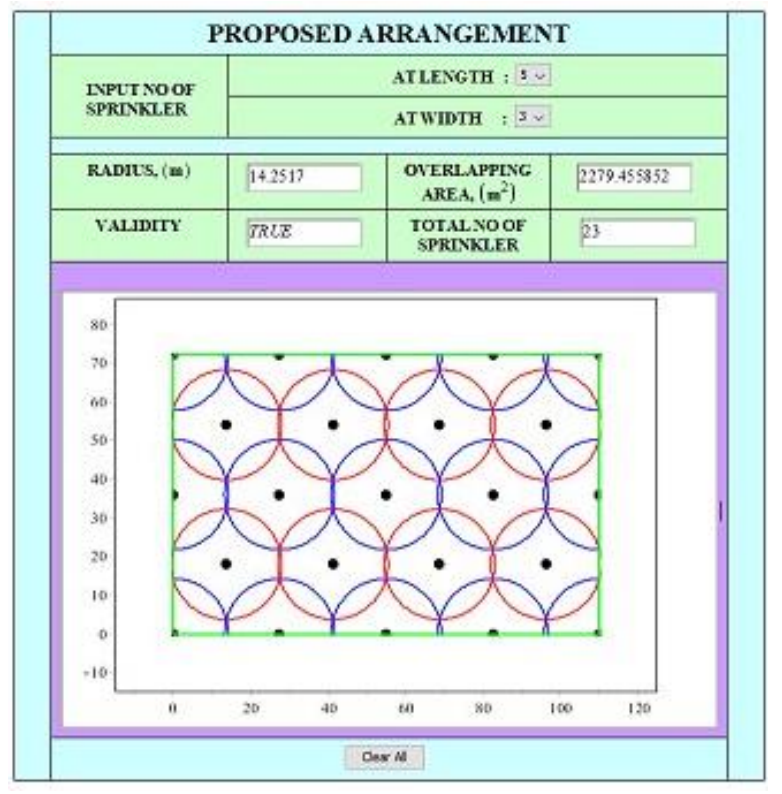

Fig. 9. Maplet interface for possible sprinkler arrangement

\section{Conclusion and Recommendation}

The sprinkler irrigation arrangement for field is successfully designed using water projection profiles from the experimental data analysis. The following conclusions can be drawn from this study

(i) The sprinkler spacing show that several factors affect in irrigation performances, wind condition, types and characteristics of sprinkler system currently used, and design and management of sprinkler systems

(ii) Compared with the effect of sprinkler spacing, it was found that the effect of number of sprinklers reduced the overlapping area.

It also incorporates water distribution pattern of each sprinkler which can be overlapped instead of common pattern for all sprinklers. Both obliquely will minimize the amount of water used and inherently reduced the maintenance cost. If the sprinkler is properly setup, all the uncertainty like overspray can be avoided. Information in this study is provided to enhance design of sprinkler systems which are the most rapidly growing form of irrigation today. Thus, the model in this study can serve as one of the support tools in deciding the design of sprinkler irrigation layout for optimal spacing with uniform water distribution without any wastage and adverse effects on crops of field. Improvement in the model is looking forward the effect of water pressure, wind speed and time of operation per set.

\section{Acknowledgements}

The authors want to dedicate special thanks and appreciations to Universiti Teknologi MARA (UiTM) and all individuals who have involved directly or indirectly in this study.

\section{References}

[1] Noerhayati, Eko, B. Dwisulo, and A. Rahmawati. "Sprinkler irrigation design with microcontroller based on IoT." In IOP Conference Series: Earth and Environmental Science, vol. 456, no. 1, p. 012063. IOP Publishing, 2020. https://doi.org/10.1088/1755-1315/456/1/012063

[2] Faci, J. M., R. Salvador, E. Playán, and Heinz Sourell. "Comparison of fixed and rotating spray plate sprinklers." Journal of Irrigation and Drainage Engineering 127, no. 4 (2001): 224-233. https://doi.org/10.1061/(ASCE)07339437(2001)127:4(224) 
[3] Alonso, Alice, Nicolas Feltz, Frédéric Gaspart, Mohamed Sbaa, and Marnik Vanclooster. "Comparative assessment of irrigation systems' performance: Case study in the Triffa agricultural district, NE Morocco." Agricultural Water Management 212 (2019): 338-348. https://doi.org/10.1016/j.agwat.2018.08.033

[4] Gul, Nazar, Ashifa Soomro, Muhammad Munir Babar, Liaquat Ali Jamali, and Bilawal Abbasi. "Effect of sprinkler and basin irrigation systems on yield and water use efficiency of canola crop." Mehran University Research Journal of Engineering \& Technology 40, no. 2 (2021): 450-458. https://doi.org/10.22581/muet1982.2102.19

[5] Ferreira, Lucas Borges, Fernando França da Cunha, and Sidney Sara Zanetti. "Selecting models for the estimation of reference evapotranspiration for irrigation scheduling purposes." PLOS ONE 16, no. 1 (2021): e0245270. https://doi.org/10.1371/journal.pone.0245270

[6] Gu, Zhe, Zhiming Qi, Rasika Burghate, Shouqi Yuan, Xiyun Jiao, and Junzeng Xu. "Irrigation scheduling approaches and applications: A review." Journal of Irrigation and Drainage Engineering 146, no. 6 (2020): 04020007. https://doi.org/10.1061/(ASCE)IR.1943-4774.0001464

[7] Vellidis, George, Vasileios Liakos, J. H. Andreis, C. D. Perry, W. M. Porter, E. M. Barnes, K. T. Morgan, Clyde Fraisse, and K. W. Migliaccio. "Development and assessment of a smartphone application for irrigation scheduling in cotton." Computers and Electronics in Agriculture $127 \quad$ (2016): $249-259$. https://doi.org/10.1016/i.compag.2016.06.021

[8] Santos, Igor Silva, Everardo Chartuni Mantovani, Luan Peroni Venancio, Fernando França da Cunha, and Catariny Cabral Aleman. "Controlled water stress in agricultural crops in brazilian cerrado." Bioscience Journal 36, no. 3 (2020): 886-895. https://doi.org/10.14393/BJ-v36n3a2020-47862

[9] Ferreira, Lucas Borges, Fernando França da Cunha, Rubens Alves de Oliveira, and Thiago Ferreira Rodrigues. "A smartphone APP for weather-based irrigation scheduling using artificial neural networks." Pesquisa Agropecuária Brasileira 55 (2020). https://doi.org/10.1590/S1678-3921.pab2020.v55.01839

[10] Damor, N. N., R. M. Solanki, J. G. Hadiyal, and B. K. Dharaiya. "Effect of drip irrigation schedules and fertigation levels on growth parameters and yields of wheat (Triticum aestivum L.)." Journal of Pharmacognosy and Phytochemistry 10, no. 2 (2021): 1546-1550.

[11] Imanudin, M. S., S. J. Priatna, B. M. B. Prayitno, and C. Arif. "Real-time irrigation scheduling for upland crop based on soil and climate characteristics of tidal lowland area in South Sumatera." In IOP Conference Series: Earth and Environmental Science, vol. 622, no. 1, p. 012051. IOP Publishing, 2021. https://doi.org/10.1088/17551315/622/1/012051

[12] Louie, Michael J., and John S. Selker. "Sprinkler head maintenance effects on water application uniformity." Journal of Irrigation and Drainage Engineering 126, no. 3 (2000): 142-148. https://doi.org/10.1061/(ASCE)07339437(2000)126:3(142)

[13] De Toro, Jose A., Gabriel F. Calvo, and Pablo Muñiz. "Two-dimensional crystallography introduced by the sprinkler watering problem." European Journal of Physics 33, no. 1 (2011): 167-177. https://doi.org/10.1088/01430807/33/1/014

[14] Pereira, Luis S. "Higher performance through combined improvements in irrigation methods and scheduling: a discussion." Agricultural Water Management 40, no. 2-3 (1999): 153-169. https://doi.org/10.1016/S03783774(98)00118-8

[15] Zhang, Lin, Gary P. Merkley, and Kasem Pinthong. "Assessing whole-field sprinkler irrigation application uniformity." Irrigation Science 31, no. 2 (2013): 87-105. https://doi.org/10.1007/s00271-011-0294-0

[16] Tarjuelo, J. Montero, J. Montero, F. T. Honrubia, J. J. Ortiz, and J. F. Ortega. "Analysis of uniformity of sprinkle irrigation in a semi-arid area." Agricultural Water Management 40, no. 2-3 (1999): 315-331. https://doi.org/10.1016/S0378-3774(99)00006-2

[17] Törnqvist, Rebecka, and Jerker Jarsjö. "Water savings through improved irrigation techniques: basin-scale quantification in semi-arid environments." Water Resources Management 26, no. 4 (2012): 949-962. https://doi.org/10.1007/s11269-011-9819-9

[18] Ben Charfi, Imen, Chiara Corbari, Drazen Skokovic, Jose Sobrino, and Marco Mancini. "Modeling of Water Distribution under Center Pivot Irrigation Technique." Journal of Irrigation and Drainage Engineering 147, no. 7 (2021): 04021024. https://doi.org/10.1061/(ASCE)IR.1943-4774.0001571

[19] Iqbal, Usman, Ijaz Ahmad, Muhammad Zaman, Noor Muhammad Khan, and Muhammad Kaleem Sarwar. "Performance evaluation of micro sprinkler irrigation system in tunnel farms and open area conditions." Fresenius Environmental Bulletin 30, no. 3 (2021): 2888-2898.

[20] Osman, M., S. Hassan, and K. Wan Yusof. "Soil moisture uniformity under low-pressure sprinkler irrigation system." Journal of Advanced Research in Materials Science 60, no. 1 (2019): 1-12.

[21] Dwomoh, F. A., Y. Shouqi, and L. Hong. "Computation model of sprinkler spacing and layout." International Journal of Engineering Sciences \& Emerging Technologies, ISSN 7, no. 1 (2014): 481-489. 
[22] Abdullah, Nur Lina, Norhidayah A. Kadir, Saiful Bahri Safaron, Nurazeera Md Suder, and Nurul Wahidah Omar. "Sprinkler arrangement for UiTM's stadium field." In AIP Conference Proceedings, vol. 1557, no. 1, pp. $252-256$. American Institute of Physics, 2013. https://doi.org/10.1063/1.4823914 